\title{
Surgical Approach to Treatment of Necrotizing Pancreatitis: Early Primary Drainage without Necrosectomy. Review of Seven Recent Cases
}

\author{
M.A. Rubtsov S.I. Galeev \\ Saint-Lucas Clinical Hospital, Saint Petersburg, Russian Federation
}

\section{Key Words}

Necrotizing pancreatitis · Early surgery $\cdot$ Procalcitonin

\begin{abstract}
Unsatisfactory results of surgery in the late course of pancreatic necrosis made us search for indications and variants of operation in the early phase of the disease. As early surgical intervention, the universal approach was used in 7 patients with necrotizing pancreatitis who had a different prevalence of the inflammatory process in the retroperitoneal space. The drainage proved to be effective and enabled us to always prevent generalized infectious complications in the later phases of the disease in absence of local complications specific for open surgery: bleeding and digestive fistulas. In spite of obvious infected process development in primary open surgery, we noticed a stable decrease in procalcitonin level following the drainage. A surgical intervention has been developed enabling one to reveal in time the volume of damaged retroperitoneal fat tissue and to drain it adequately in compliance with the process prevalence, thus avoiding septic complications in the late phase of the disease. The method's advantage involves refusal from necrosectomy in primary intervention, weekly staged revisions of the retroperitoneal space via formed contrapertures as dictated by evolution of the necrotic process in the gland.
\end{abstract}

\section{Introduction}

Overall mortality in necrotizing pancreatitis still remains high: up to $30 \%$ [1]. Extended pancreatic necrosis presents a special problem in clinical surgery. According to Isenmann et al., in spite of a noticeable progress in intensive care, mortality has remained practically unchanged in cases of extended necrosis even at specialized centres in the period from the 1980s to the 1990s [2]. The primarily conservative tactics in extended 
severe pancreatitis has exerted just a minimal effect upon overall mortality, entailing a change in the death modality only: once the patients died of noninfectious pancreatogenic shock, now they die of septic complications [3]. Those surgeons who were brave enough to operate early showed the efficacy of such tactics irrespective of the necrosis bacterial status [4]. There are, however, some data on an increase in mortality in early necrosectomy or resection of the pancreas [5]. We have found no literature data that could convince us of absence of the early open drainage positive effect upon proceeding of severe pancreatitis.

The main rules of surgery in pancreatic necrosis were formulated by Moynihan back in 1925 [6]. They involved isolation of the pancreas from the abdominal cavity and cellular fat spaces and adequate drainage of peripancreatically accumulated liquid. Recent experimental studies enrich our understanding of the pathogenetic effect of this kind of interventions, having paid specific attention to the retroperitoneal compartment syndrome. Thus drainage of the pancreas entails regression in gland ischemia and, consequently, might interrupt the destructive process in this organ [7].

\section{Patients and Methods}

From 2006 to 2007 we encountered 7 patients with necrotizing pancreatitis at the surgery department of Saint Lukas Hospital (Saint Petersburg). Six of them had more than $50 \%$ of the gland affected (based on helical CT findings). In one case CT was not performed (extended necrosis of the pancreas was verified during autopsy), in another the volume of devital tissue was evaluated as 30-50\%. All patients were operated during 7 days after admission. Mean duration of the disease before operation was 4 days or $106 \mathrm{~h}$ (range 21-348 h). There were 5 men and 2 women whose mean age was 47.6 years (range 26-65). Three subjects had chronic alcohol abuse, in one case underlying pancreatitis developed after $2 / 3$ gastrectomy for peptic ulcer complicated by pyloroduodenal stenosis. In 3 other patients the etiology of pancreatitis remained unknown. The average APACHE II score level before surgery was 19.4 (range 12-26).

The surgery we adopted consists of opening the abdomen by upper midline incision, revision of the abdominal cavity with direct attention on the transverse mesocolon, small bowel mesentery, right and left flanks, iliac fosses and pelvis to define extent of retroperitoneal exudation. Then division of the gastrocolic omentum comes with further isolation of the pancreas by incising the posterior layer of the lesser sac above the superior and inferior edges of the gland. Inferior edge mobilization is usually performed from the superior mesentery vessels to the distal part of the pancreatic tail. This manipulation gives vent to fluid localized near the pancreas, making a good approach to fluid collections of the transverse mesocolon and small bowel mesentery. An extremely important stage of operation is wide extraperitoneal approach to the lesser sac and left paracolon-retroperitoneal omentolumbostomy. It is applied in cases of left paracolon affected mainly. The paracolic space and lesser sac are opened bimanually: The fingers of the left hand form a canal under the tail of the pancreas and the spleen between the splenic flexure of the colon and the lower pole of the left kidney to the posterior abdominal wall. The right hand is placed on the lumbar area to ensure proper movement of the left one at same moment (fig. 1). Then the surgeon makes an oblique 5-7 cm incision anteriolly to the apex of the twelfth rib. It becomes possible to enter the lesser sac after severing the muscles.

The operation provides for no mobilizing of the splenic flexure of the colon or Kocher's mobilization of the duodenum, or opening of the parietal peritoneum of the left gutter in order to avoid contact between the retroperitoneal exudate with the free abdominal cavity in all stages of treatment. If need be (extension of the process up to the iliac fossa and small pelvis), the omentolumbostomy can be technically complemented with an extraperitoneal contraperture applied along the margin of the iliac spine (fig. 2). In case of extension of the exudation into the retroduodenal and paracolic fat tissue on the right, we form an extraperitoneal contraperture in the lumbar area analogous to the left-sided lumbostoma. This approach has no intercommunication with the omental bursa cavity but enables one to control right retroperitoneal fat tissue spaces.

The operation ends with installation of two drainage tubes ( 0.59 ") via the omentolumbostoma into the lesser sac and the left paracolic space. In addition, a tube with analogous diameter is installed in the omental bursa via the Winslow aperture. Extraperitonization of approach to the lesser sac is performed 
by means of forming an epigastric omentolaparostoma. The omental bursa and the drained retroperitoneal spaces are packed with gauze and laid open, thus forming large enough wound canals in the area of omentolumbo- and laparostomas for performing subsequent planned re-explorations and necrosectomies.

The first planned re-exploration is performed not before the 6th to 7th day from the moment of the first operation. In this period, as a rule, demarcation between healthy and necrotized tissue of the pancreas becomes evident. The necrosis foci, however, are still closely connected with healthy tissue, so the early extensive necrosectomy is fraught with complications, including dangerous bleeding. By this time, the fat tissue sequesters are mobile, as a rule, and may be easily removed. One should emphasize that manipulations in the omental bursa and retroperitoneal space are carried out within the above contrapertures (through the established pathways). The next staged intervention is performed on the 12th to 14th days after the operation. We have established that just at this time an active process of rejection of the pancreas sequesters will start. In this period, the character of the omental bursa discharge changes: purulent exudation appears.

The variant of used draining intervention in our group of patients depended on the prevalence of the inflammatory process within the retroperitoneal space as established during laparotomy (table 1). Monitoring of the septic complications of the disease was performed with the aid of semi-quantitative test for blood serum procalcitonin (PCT-Q, B.R.A.M.S.). The test was performed weekly, i.e. prior to each sequesterectomy and in appearance of symptoms suspicious of occurrence of undrained foci of infection. Process in the wound at PCT-Q values exceeding $2 \mathrm{ng} / \mathrm{ml}$ was estimated by us as infectious, inadequately drained.

\section{Results}

In 6 patients, according to bacteriological study of the material obtained during surgery, the process was sterile, and only in 1 patient it was infected. The average number of repeated interventions (except for the patient who died early in the postoperative period) made under general anesthesia was 4.2. Subsequent interventions were made as requested under mild sedation, in a dressing ward. Two serious complications occurred: (1) Hypocoagulation with profuse bleeding during and after the surgical intervention (the patient had been admitted 216 hours after falling ill, with an APACHE II of 26, severe acute renal failure and anuria (two hemodialysis procedures). The necrosis area as revealed with the aid of CT was estimated as $30-50 \%$. In intraoperative sampling, the process was sterile. The bleeding was stopped by means of intense conservative measures. (2) Bilateral pneumonia complicated by lung abscesses, with respiratory failure (this particular complication caused death of one patient with infected pancreatic necrosis who had been admitted to the hospital $348 \mathrm{~h}$ after onset of acute abdominal pain). APACHE II at the moment of admission was 18. Autopsy revealed extensive necrosis of the gland with thrombosis of spleen vessels, spleen infarction, widespread purulent lesion of retroperitoneal cellular spaces and septic pulmonary complications. The main cause of the death was multiorgan failure secondary to severe sepsis. In three patients pancreatic fistulas occurred which closed spontaneously within the term of 3 weeks to 3 months postoperatively. In all cases postoperative ventral hernias developed. Out of 7 persons, 1 died (mortality $14.2 \%$ ). The average hospital stay was 45 days (range $4-70$ ). Data on procalcitonin monitoring are listed in table 2.

\section{Discussion}

The suggested surgical intervention was performed by us within the first week as of the moment of admission of a patient to the department, irrespective of necrosis bacterial status. In our opinion, early laparotomy, which per se is not a traumatic intervention, enables one to determine severity of pancreatitis more precisely, to prognosticate its 
possible outcomes and to preventively drain the areas of probable accumulation of the exudation. Apparently not the gland necrosis alone but also a parapancreatitis constitute the morphological substrate of the inflammatory process in the pancreas entailing obvious intoxication and failure of many organs. And whereas prior to the operation one can judge the gland necrosis area with the aid of CT, one fails, as a rule, to obtain precise estimation of the extent of the process in the retroperitoneal space during the early stage of pancreatitis [8]. The dependence of severity of the retroperitoneal changes on the gland necrosis area is quite comprehensible. However, one cannot ignore reports by some authors indicating the absence of any correlation between systemic inflammatory response syndrome and the degree of the gland lesion [9]. Thus parapancreatitis seems to be an independent source of intoxication and organ dysfunction in case of necrotizing pancreatitis. The volume of retroperitoneal exudation, however, does not always depend on the extension of gland necrosis. Therefore, timely revealing of widespread retroperitoneal exudation as a possible predictor of grave proceeding of the pancreatitis is an independent problem in itself that requires intense attention of the surgeon. Open interventions performed in the phase of purulent complications are limited in their ability for precise visual control over the liquid accumulations. This is corroborated by the fact that the main cause of recurrent septic complications in late surgery involves undrained or poorly drained accumulations of infected exudate. Moreover, midline laparotomy is the most frequently used approach in acute abdominal catastrophes in general surgery departments. Therefore the surgeon who opens the abdominal cavity and encounters a destructive process in the pancreas must be capable of performing adequate completion of the surgery. Preventive drainage of affected fat-cellular spaces in an open way, provided they are isolated from the free abdominal cavity, prevents seizure of new areas by the inflammatory process and inhibits development of tied liquid accumulations containing infected material. We use the midline approach for forming the omentobursostoma in all cases of pancreatic necrosis drainage. We believe it inexpedient not to use the already made laparotomic cut as some authors recommend [10]. According to our own data, the omentobursostoma creates optimal conditions for performing delayed necrosectomy (fig. 3).

The problem of necrosectomy in primary intervention is an issue of principle. We believe such necrosectomy to be poorly substantiated and have not used it since 1992 . Early sequesterectomy has a number of drawbacks: it is technically difficult to perform under absence of a clear demarcation between the necrotized and the living tissues, and it is associated with the necessity to remove living tissues which is accompanied by obvious blood loss and formation of pancreatic and digestive fistulas. The necessity of a clear demarcation is also indicated by the adherents of maximally delayed interventions [11]. Indeed, necrosectomy performed under conditions of clear localization of dead tissue is quite an adequate intervention. However, the patient is operated upon when he or she has already existing (and possibly for a long time) infected loci; and even if adequate necrosectomy in primary delayed intervention enables one to control the area of destruction in the pancreas and retroperitoneal spaces, still it does not indemnify from development of generalized septic complications. In addition, the surgery performed on the 3rd week of the disease is incomparably more difficult than the early one. Thus the authors, possessing vast experience in the treatment of infected necrotizing pancreatitis, simply have to intervene in cases of well-formed pancreatogenic infiltration, indicating the difficulty of approach to the lesser sac because of bounded inflammatory process in hepatogastric and gastrocolic ligaments which requires new and, in our opinion, not the best variants of the approach to the pancreas, for instance, via the mesentery of the transverse colon [12]. 
In spite of apparent infection in tissues during the primary intervention, in our series a stable drop in procalcitonin concentration depended, probably, on the absence of closed cavities with liquid infected exudation rather than on adequacy of the primary necrosectomy.

The laparotomy is terminated with open packing, thus creating optimal conditions not only for exudate outflow but also for subsequent staged explorations by means of forming contrapertures with large enough diameter through which it will be possible to perform necrosectomy, to treat the pancreas area and the area of retroperitoneal fat tissue. The staged treatment and necrosectomy are performed at a weekly interval which is dictated by evolution of the destructive-inflammatory process in the gland and fat tissue; so 7 days after the first surgery is the optimal moment for removal of rejected cellular sequesters. The pancreas sequesters are readily removable usually in 2 weeks' time.

We used early draining intervention with delayed necrosectomy in 7 patients. The method's advantages are as follows: little damage (minimization of trauma during the first intervention, the delayed character of necrosectomy), relatively simple and adequate drainage of the affected areas, the complete treatment enabling one to achieve good long-term results on account of diminishing the probability of occurrence of the symptom cysts and abscesses of the pancreas. The main disadvantage of the method lies in that only patients with process that could be treated in a conservative way are subjected to surgical intervention. There are, however, no literature data that indicate an increase in mortality after early strict draining interventions in sterile pancreatic necrosis.

Table 1. Type of surgery and spreading of the inflammatory process in the retroperitoneal space

\begin{tabular}{lll}
\hline Type of surgery & $\begin{array}{l}\text { Spreading of the inflammatory process in } \\
\text { the retroperitoneal space }\end{array}$ & $\begin{array}{l}\text { No. of } \\
\text { patients }\end{array}$ \\
\hline Epigastric omentobursostomy & $\begin{array}{l}\text { Parapancreatic space, Kocher's space, } \\
\text { mesocolon }\end{array}$ & 1 \\
\hline $\begin{array}{l}\text { Epigastric omentobursostomy + access to the } \\
\text { right retroperitoneal spaces }\end{array}$ & $\begin{array}{l}\text { Parapancreatic space, Kocher's space, } \\
\text { mesocolon, paracolon (right) }\end{array}$ & 1 \\
\hline $\begin{array}{l}\text { Epigastric omentobursostomy + lumbostomy } \\
\text { (left) }\end{array}$ & $\begin{array}{l}\text { Parapancreatic space, Kocher's space, } \\
\text { mesocolon, paracolon (left) }\end{array}$ & 3 \\
\hline $\begin{array}{l}\text { Epigastric omentobursostomy + lumbostomy } \\
\text { (left) + access to the left iliac fossa (fig. 2) }\end{array}$ & $\begin{array}{l}\text { Parapancreatic space, Kocher's space, } \\
\text { mesocolon, paracolon (left), iliac fossa (left) }\end{array}$ & 1 \\
\hline $\begin{array}{l}\text { Epigastric omentobursostomy + lumbostomy } \\
\text { (left) + access to the left iliac fossa + access to } \\
\text { the right retroperitoneal spaces }\end{array}$ & $\begin{array}{l}\text { Extended parapancreatitis: parapancreatic } \\
\text { space, Kocher's space, mesocolon, } \\
\text { paracolon (left), paracolon (right), iliac } \\
\text { fossa (left) }\end{array}$ & 1 \\
\hline
\end{tabular}


Table 2. Procalcitonin (PCT) monitoring profile

\begin{tabular}{llllll}
\hline $\begin{array}{l}\text { No. of } \\
\text { patients }\end{array}$ & $\begin{array}{l}\text { PCT at admission } \\
\mathrm{ng} / \mathrm{ml}\end{array}$ & $\begin{array}{l}\text { PCT at week 1 } \\
\mathrm{ng} / \mathrm{ml}\end{array}$ & $\begin{array}{l}\text { PCT at week 2 } \\
\mathrm{ng} / \mathrm{ml}\end{array}$ & $\begin{array}{l}\text { PCT at week 3 } \\
\mathrm{ng} / \mathrm{ml}\end{array}$ & $\begin{array}{l}\text { Outcome } \\
1\end{array}<^{<0.5}$ \\
\hline$\geq 0.5$ & $<0.5$ & $<0.5$ & $<0.5$ & survived \\
1 & $\geq 0.5$ & $<0.5$ & $<0.5$ & $<0.5$ & survived \\
3 & $\geq 0.5$ & $\geq 0.5$ & $<0.5$ & $<0.5$ & survived \\
1 & $\geq 2$ & $\geq 0.5$ & $\geq 0.5$ & $<0.5$ & survived \\
1 & - & - & - & died \\
\hline
\end{tabular}

Fig. 1. Technique of omentolumbostomy setting.

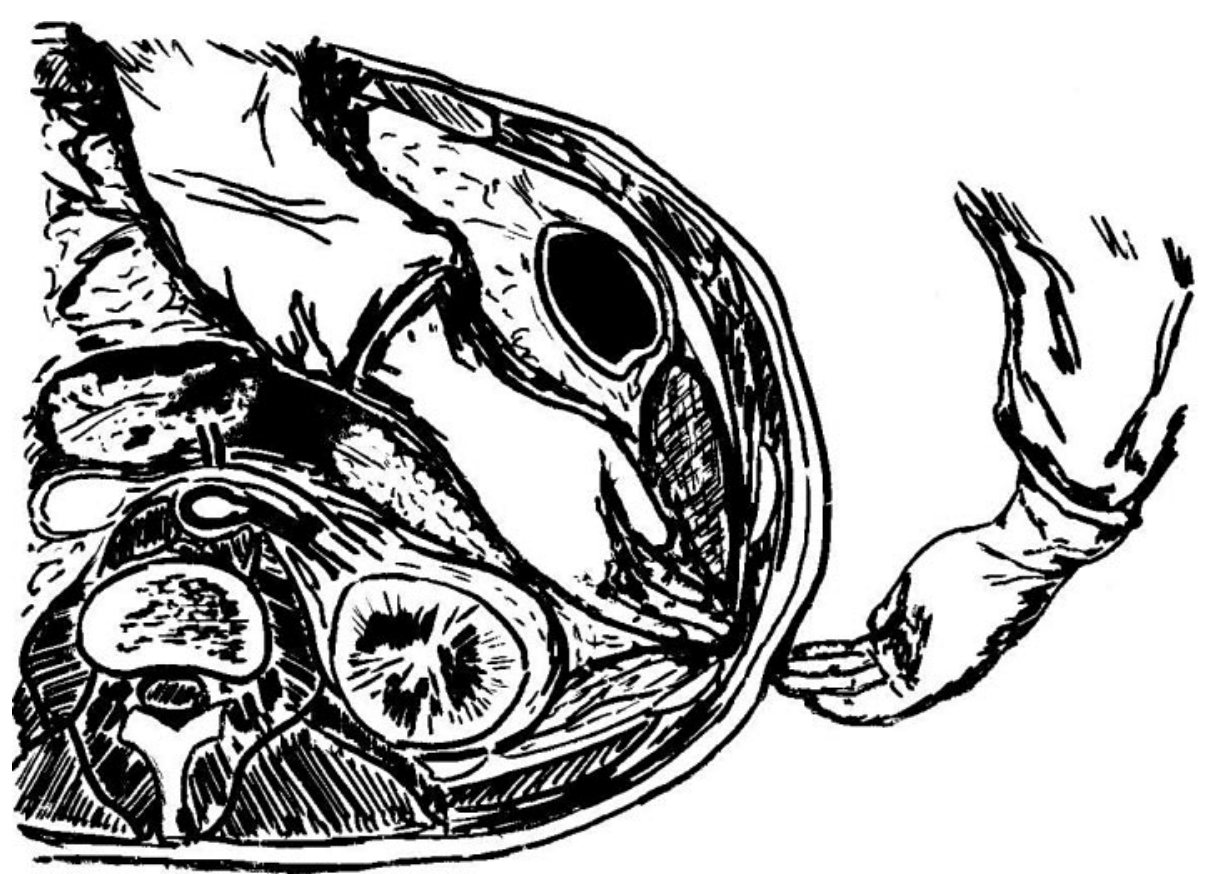


Fig. 2. Access routes for open packing of lesser sac and left retroperitoneal spaces (paracolon, iliac fossa).

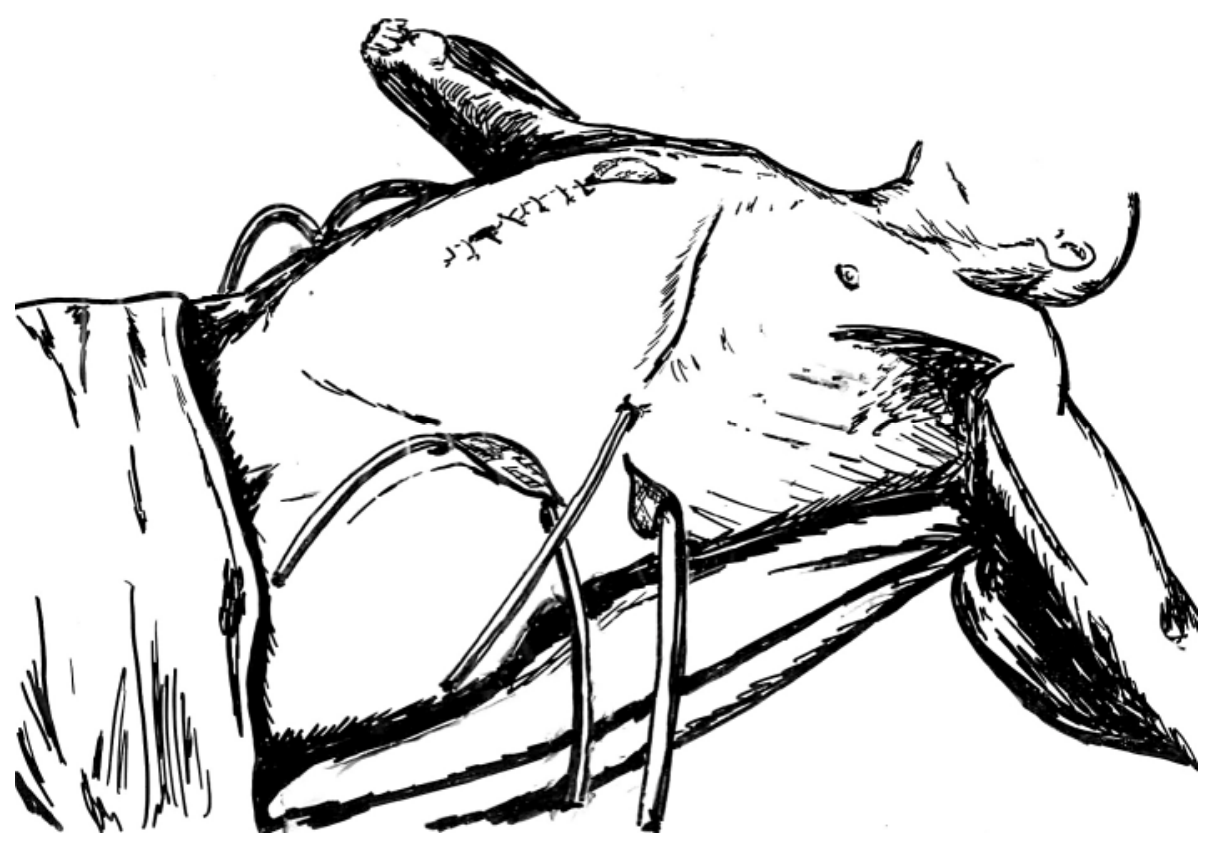

Fig. 3. Delayed necrosectomy. Large sequestra removal (arrow) through the established epigastric pathway.

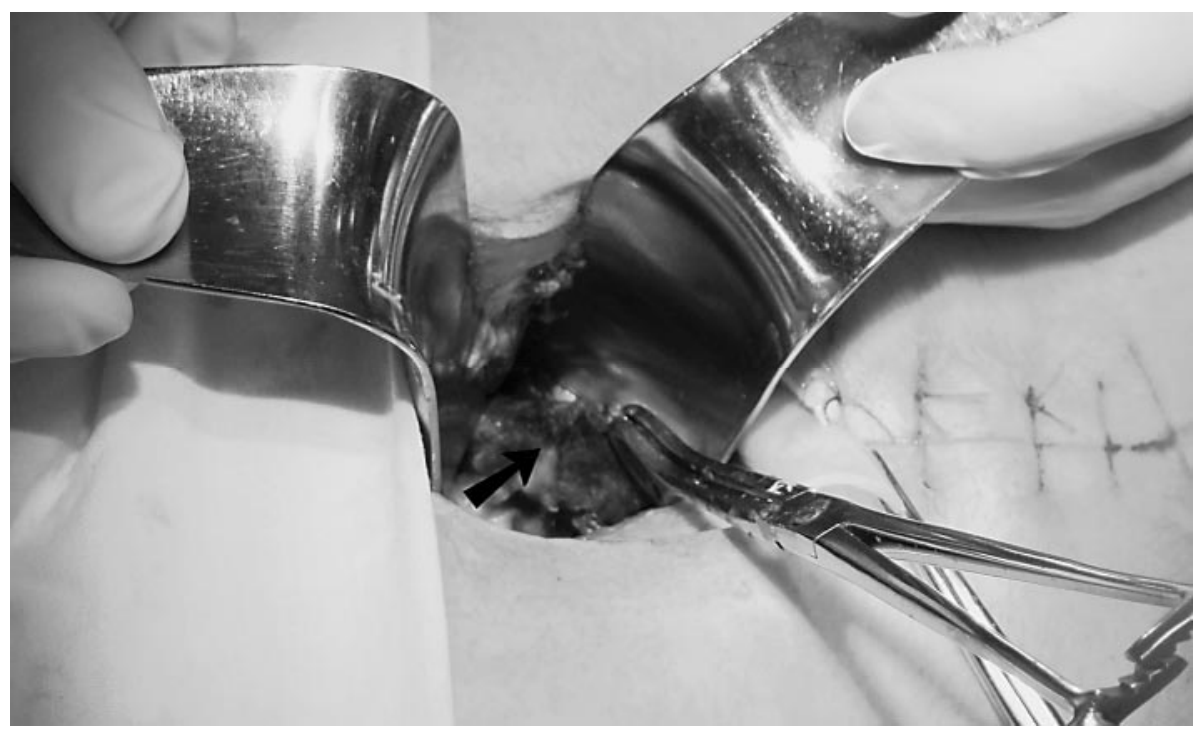




\section{References}

1 Baron T, Morgan D: Acute necrotizing pancreatitis. N Engl J Med 1999;340:14121417.

2 Isenmann R, Rau B, Zoellner U, Beger HB: Management of patients with extended pancreatic necrosis. Pancreatology 2001;1:63-68.

-3 Bradley E: Management of infected pancreatic necrosis by open drainage. Ann Surg 1987;206:542-550.

-4 Rattner D, Legermate D, Lee M, et al: Early surgical debridement of symptomatic pancreatic necrosis is beneficial irrespective of infection. Am J Surg 1992;163:105-109; discussion 109-110.

5 Mier J, Leon EL, Castillo A, et al: Early versus late necrosectomy in severe necrotizing pancreatitis. Am J Surg 1997;173:71-75.

6 Moynihan B: Acute pancreatitis. Ann Surg 1925;81:132-142.

7 Kotzampassi K: Retroperitoneal compartment pressure elevation impairs pancreatic blood flow. Pancreas 2007;35:169-172.

8 Martin DR, Karabulut N, Yang M, et al: High signal peripancreatic fat on fat-supressed spoiled gradient echo imaging in acute pancreatitis: preliminary evaluation of the prognostic significance. J Magn Reson Imaging 2003;18:49-58.

-9 Wilson GP, Manji M, Neoptolemos PJ: Acute pancreatitis as a model of sepsis. J Antimicrob Chemother 1998;41(suppl A):51-63.

-10 Villazon SA, Villazon DO, Terrazas EF, Raña R: Retroperitoneal drainage in the management of the septic phase of severe acute pancreatitis. World J Surg 1991;15:103-107; discussion 107-108.

11 Howard MJ: Delayed debridement and external drainage of massive pancreatic or peripancreatic necrosis. Surg Gynecol Obstet 1989;168:25-29.

$\checkmark 12$ Gotzinger P: Operative treatment of severe acute pancreatitis. Eur Surg 2007;39:327. 